\title{
Raman Microscopy and Remote Laser Raman Spectroscopy in Art History and Conservation Science: Analysis of Three Illuminated Gutenberg Bibles
}

\author{
G. D. Smith,* T. D. Chaplin,* R. J. H. Clark,* K. Jensen,** and D. Jacobs** \\ *Christopher Ingold Laboratories, University College London, 20 Gordon Street, London WC1H \\ 0AJ, U.K. \\ **The British Library, 96 Euston Road, London NW1 2DB, U.K.
}

Raman microscopy has proven uniquely suited for the identification and study of mineral and organic pigments in art historical research and conservation science [1]. The qualities that make this technique appropriate to the study of artefacts and artwork include its molecular specificity, high spatial resolution $(=1 \mu \mathrm{m})$, broad spectral range $\left(4000\right.$ to $\left.10 \mathrm{~cm}^{-1}\right)$, and non-destructiveness. Recent instrumental advances that include highly efficient optics, sensitive CCD detectors, compact nearinfrared (NIR) lasers, and remote laser probes have improved immensely the spectral quality of these systems while reducing instrument size and measurement time and facilitating the application of the technique to the study of non-uniform or large samples [2,3]. These improvements have led to increased interest in Raman microscopy and remote Raman spectroscopy among conservation scientists and archaeometrists.

The authors have recently performed an on-site Raman analysis of the palettes of three illuminated Johannes Gutenberg Bibles. Gutenberg is widely accepted as being responsible for the invention of printing in the Western world using movable metal type, an accomplishment largely associated with his production of approximately 180 Bibles in 1455 A.D. [4,5]. Only 48 of those survive today; many of these are only partial and several are in serious need of conservation. Three complete and well preserved volumes are held in the vicinity of London, England - at the British Library, Eton College, and Lambeth Palace. They, like other volumes world-wide, have been illuminated by hand. The illuminations on the British Library and Eton College copies are similar, consisting of interwoven flora and fauna around the columns of printed text (Figure 1). Those on the Lambeth Palace copy are different; the major illuminations consist of geometric patterns in blue, white and metallic gold while the minor illuminations show greater similarity to the other English illuminated copies.

Previous analyses of Gutenberg Bibles have focused on the formulations of the printing inks [6,7]. In this study, Raman microscopy was used to identify the pigments used to illuminate the three copies of the Gutenberg Bible in order to compare the palettes of the different copies and those suggested by contemporaneous model illumination books [8,9]. The illuminations on the British Library copy of the Bible were analysed in situ. Due to restricted access to the Bibles at Eton College and Lambeth Palace, debris material from these copies was collected from the gutters of the illuminated pages so that no direct sampling was performed. The material was examined using a Renishaw System 1000 Raman spectrometer with a $632.8 \mathrm{~nm}$ HeNe laser. The instrument was used both with a microscope and with a remote laser probe. The Raman spectra collected from the pigment flakes and from the intact artefact were compared to spectral libraries of reference pigments in order to identify the materials $[10,11]$. 
The palettes identified for the three copies of the Gutenberg Bible are roughly similar and consist entirely of those colourants known to be in common use in the $15^{\text {th }}$ century. The similarity of the style of the British Library and Eton College copies may indicate that they were illuminated at the same time, possibly even by the same hand. This possibility was supported by the occurrence of lead tin yellow (Type $1, \mathrm{~Pb}_{2} \mathrm{SnO}_{4}$ ) on both the British Library and Eton Bibles. Lead tin yellow was not found on the stylistically different Lambeth Bible, rather true gold paint and gilding were used extensively in its illumination. The Lambeth Bible is likely to have been decorated by a different hand, possibly for a wealthier owner due to the abundant use of gold. The detailed illuminations and precious metals found on the Lambeth Bible led conservators originally to surmise that the deep blue pigment appearing throughout it was lapis lazuli $\left(\mathrm{Na}_{8}\left[\mathrm{Al}_{6} \mathrm{Si}_{6} \mathrm{O}_{24}\right] \mathrm{S}_{\mathrm{n}}\right)$, an expensive mineral pigment laboriously extracted from lazurite found in Afghanistan. Surprisingly, the blue pigment was identified by its Raman spectrum as a cheaper colourant, azurite $\left(2 \mathrm{CuCO}_{3} \bullet \mathrm{Cu}(\mathrm{OH})_{2}\right)$. This new information will have a significant impact on any future conservation or restoration of the illuminations. Further analyses of Gutenberg Bibles held outside England will be undertaken for comparison to those already studied and to establish similarities in illumination styles and palettes for these historical artefacts.

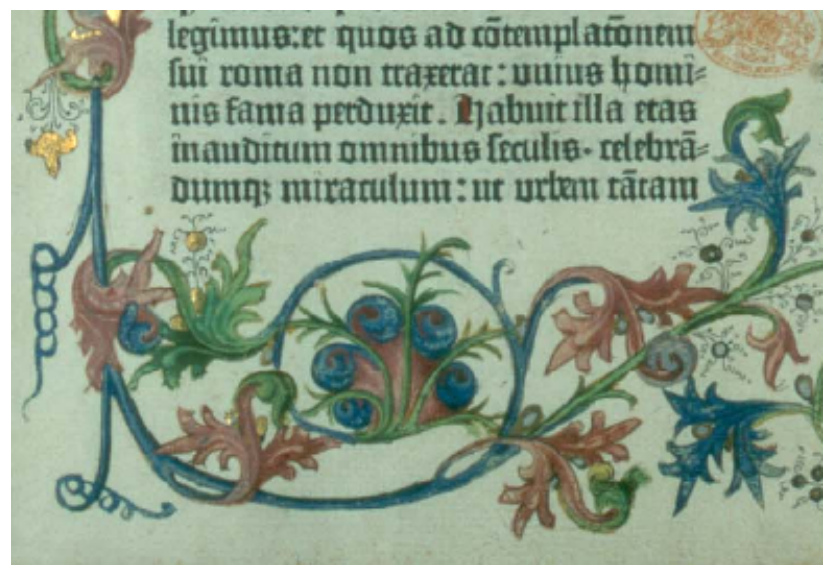

Figure 1. Example of the illumination from the base of the Prologue page of the Gutenberg Bible bequeathed to the British Library by the family of King George III.

\section{References}

[1] G. D. Smith and R. J. H. Clark, Rev. Conserv. 2 (2002) 96.

[2] B. P. Lenain, Analusis 28 (2000) 11.

[3] R. J. H. Clark and P. J. Gibbs, J. Arch. Sci. 25 (1998) 261.

[4] G. Bechtel, Gutenberg et l'invention de l'imprimerie: Une ênquete, Paris, 1992.

[5] M. Davies, The Gutenberg Bible, London, 1996.

[6] T. A. Cahill et al., Archaeometry 26 (1984) 3.

[7] R. N. Schwab et al., Papers Bibliogr. Soc. Am. 79(1985) 375.

[8] H. Lehmann-Haupt, The Göttingen Model Book, University of Missouri, 1978.

[9] B. von Rufach, Illuminierbuch, künstlich alle Farben zu machen.

[10] I. M. Bell et al., Spectrochim. Acta A 53 (1997) 2159.

[11] L. Burgio and R. J. H. Clark, Spectrochim. Acta A 57 (2001) 1491. 